Supporting information for the manuscript

\title{
Diffusion Based Deprotection in Mesoporous Materials: A Strategy for Differential Functionalization of Porous Silica Particles
}

Kai Cheng and Christopher C. Landry

Department of Chemistry, 82 University Place

University of Vermont, Burlington, VT 05405

Table S1. Comparison of Organic Loadings Determined by TGA and UV/Visible Spectrophotometry on Selected Samples From Table 1.

\begin{tabular}{cccccc}
\hline & \multicolumn{2}{c}{$\mathrm{TGA}^{\mathrm{n}}$} & & UV/Visible & \\
\cline { 2 - 3 } Sample & $\begin{array}{c}\text { Weight } \\
\text { loss } \\
(\%)\end{array}$ & $\begin{array}{c}\Gamma^{\mathrm{a}} \\
(\mathrm{mmol} /\end{array}$ & & $\begin{array}{c}\Gamma \\
(\mathrm{mmol} /\end{array}$ & \\
$\left.\mathrm{g} \mathrm{SiO}_{2}\right)$ & & $\left.\mathrm{g} \mathrm{SiO}_{2}\right)$ & $\Gamma_{\mathrm{TGA}} / \Gamma_{\mathrm{UV}-V i s i b l e}$ \\
\hline APMS-3-Fmoc-33 & 13.44 & 0.554 & & $0.550 \pm 0.11$ & 1.01 \\
APMS-3-Fmoc-45 & 15.31 & 0.645 & & $0.619 \pm 0.10$ & 1.04 \\
APMS-3-Fmoc-60 & 17.13 & 0.737 & & $0.708 \pm 0.10$ & 1.04 \\
APMS-3-Fmoc-100 & 19.98 & 0.891 & & $0.874 \pm 0.13$ & 1.02 \\
APMS-3-Fmoc-135 & 21.69 & 0.988 & & $0.965 \pm 0.14$ & 1.02 \\
APMS-3-Fmoc-200 & 23.76 & 1.11 & & $1.02 \pm 0.17$ & 1.09 \\
\hline
\end{tabular}

${ }^{\mathrm{a}} \Gamma=$ total amount of organic loading (linker plus Fmoc) 
Table S2. Parameters from Equations 3 and 5 for the Release of Fmoc-Piperidine Adducts Under Various Conditions.

\begin{tabular}{|c|c|c|c|c|c|c|c|c|c|c|c|c|}
\hline Samples & Temperature & $\begin{array}{l}\text { Piperidine } \\
\text { (vol \%) }\end{array}$ & $\begin{array}{l}\mathrm{Y}_{0} \\
(\%)\end{array}$ & $\begin{array}{l}Y_{\max } \\
(\%)\end{array}$ & $\begin{array}{c}\mathrm{T}_{1 / 2} \\
(\mathrm{~min})\end{array}$ & $\mathrm{H}$ & $\mathrm{R}^{2}$ & $\mathrm{~K}_{\mathrm{m}}$ & $\begin{array}{c}\begin{array}{c}\mathrm{T}_{\mathrm{m}} \\
(\mathrm{min})\end{array} \\
\end{array}$ & $\mathrm{K}_{\mathrm{lag}}$ & $\begin{array}{c}\mathrm{T}_{\mathrm{Lag}} \\
(\mathrm{min})\end{array}$ & $\begin{array}{l}Y_{\text {Lag }} \\
(\%) \\
\end{array}$ \\
\hline \multirow{9}{*}{ APMS-3-Fmoc-100 } & 25 & 2 & $4.39 \pm 0.48$ & $89.96 \pm 1.29$ & $233.8 \pm 4.4$ & $2.72 \pm 0.11$ & 0.998 & 0.302 & 175.6 & 0.0766 & 81.74 & 6.26 \\
\hline & 25 & 5 & $1.56 \pm 1.21$ & $82.41 \pm 2.07$ & $129.1 \pm 5.6$ & $2.04 \pm 0.17$ & 0.995 & 0.420 & 76.38 & 0.176 & 26.29 & 4.63 \\
\hline & 25 & 10 & $2.66 \pm 0.81$ & $81.57 \pm 1.50$ & $105.7 \pm 2.8$ & $1.98 \pm 0.10$ & 0.997 & 0.500 & 59.90 & 0.278 & 19.92 & 5.54 \\
\hline & 25 & 20 & $4.26 \pm 0.59$ & $73.93 \pm 1.02$ & $95.42 \pm 1.92$ & $2.05 \pm 0.08$ & 0.998 & 0.509 & 56.57 & 0.359 & 19.53 & 7.02 \\
\hline & 25 & 40 & $5.65 \pm 0.66$ & $67.01 \pm 1.17$ & $94.93 \pm 1.83$ & $2.01 \pm 0.10$ & 0.997 & 0.460 & 57.24 & 0.420 & 19.22 & 8.07 \\
\hline & 30 & 2 & $2.16 \pm 0.86$ & $89.01 \pm 1.48$ & $106.9 \pm 2.3$ & $2.77 \pm 0.16$ & 0.997 & 0.658 & 81.53 & 0.184 & 38.16 & 7.01 \\
\hline & 30 & 5 & $2.81 \pm 1.03$ & $87.54 \pm 1.60$ & $72.94 \pm 2.01$ & $2.02 \pm 0.10$ & 0.997 & 0.783 & 42.62 & 0.416 & 14.39 & 5.99 \\
\hline & 40 & 2 & $2.91 \pm 0.60$ & $94.19 \pm 0.77$ & $39.18 \pm 0.46$ & $2.77 \pm 0.07$ & 0.999 & 1.903 & 30.01 & 0.576 & 14.00 & 8.06 \\
\hline & 40 & 5 & $2.75 \pm 1.29$ & $90.03 \pm 1.54$ & $24.35 \pm 0.61$ & $2.44 \pm 0.13$ & 0.997 & 2.67 & 17.16 & 0.984 & 7.093 & 6.98 \\
\hline APMS-3-Fmoc-33 & 25 & 5 & - & - & $1.92^{\mathrm{a}}$ & - & - & - & - & - & - & - \\
\hline APMS-3-Fmoc-45 & 25 & 5 & - & - & $4.03^{\mathrm{a}}$ & - & - & - & - & - & - & - \\
\hline APMS-3-Fmoc-60 & 25 & 5 & $7.63 \pm 0.96$ & $82.16 \pm 1.55$ & $68.78 \pm 2.04$ & $2.13 \pm 0.12$ & 0.998 & 0.800 & 42.65 & 0.708 & 15.37 & 10.9 \\
\hline APMS-3-Fmoc-100 & 25 & 5 & $2.22 \pm 1.21$ & $81.03 \pm 2.70$ & $129.1 \pm 5.6$ & $2.04 \pm 0.17$ & 0.995 & 0.412 & 75.81 & 0.199 & 26.18 & 5.22 \\
\hline APMS-3-Fmoc-135 & 25 & 5 & $3.24 \pm 0.74$ & $90.96 \pm 2.25$ & $312.0 \pm 9.8$ & $2.18 \pm 0.12$ & 0.998 & 0.198 & 198.1 & 0.0946 & 73.65 & 6.97 \\
\hline APMS-3-Fmoc-200 & 25 & 5 & $4.50 \pm 0.95$ & $94.30 \pm 6.21$ & $591.1 \pm 35.5$ & $2.97 \pm 0.39$ & 0.981 & 0.133 & 465.6 & 0.0431 & 231.9 & 9.99 \\
\hline APMS-11-Fmoc-50 & 25 & 5 & - & - & $16.18^{\mathrm{a}}$ & - & - & - & - & - & & - \\
\hline APMS-11-Fmoc-200 & 25 & 5 & $10.8 \pm 1.1$ & $82.50 \pm 2.11$ & $128.3 \pm 5.5$ & $1.48 \pm 0.09$ & 0.998 & 0.392 & 43.75 & 1.47 & 8.293 & 12.2 \\
\hline Nucleosil-3-Fmoc-200 & 25 & 5 & $15.4 \pm 2.3$ & $82.60 \pm 3.81$ & $33.28 \pm 2.49$ & $2.03 \pm 0.34$ & 0.998 & 1.62 & 19.95 & 2.77 & 6.629 & 18.4 \\
\hline Nucleosil-11-Fmoc-200 & 25 & 5 & $8.99 \pm 1.76$ & $87.54 \pm 2.33$ & $45.45 \pm 1.82$ & $1.62 \pm 0.10$ & 0.996 & 1.17 & 19.09 & 2.48 & 4.405 & 10.9 \\
\hline
\end{tabular}

${ }^{\mathrm{a}} \mathrm{T}_{1 / 2}$ for these samples with low organosilane loadings were estimated directly from the release curves. 
Figure S1. 3D structures of Fmoc-APTES and Fmoc-AUTES from simple modeling calculations (Chem Finder for Office, 2005, Cambridge Soft).

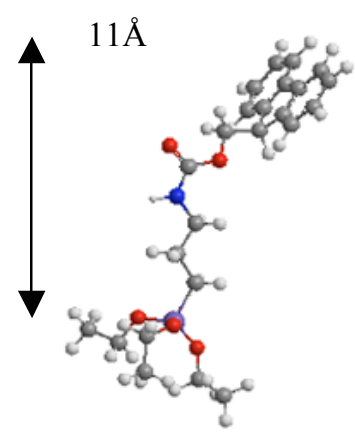

Fmoc-APTES

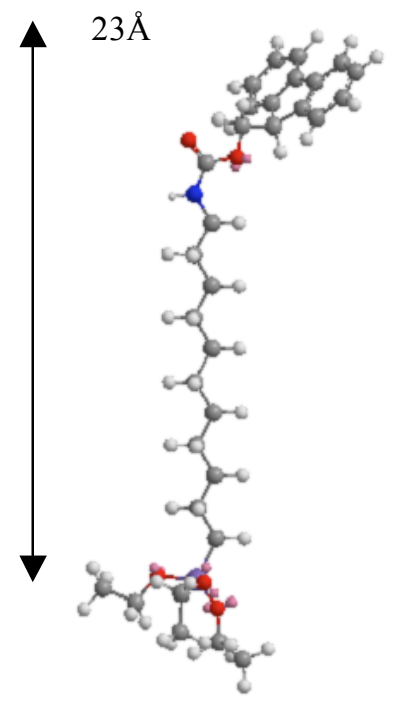

Fmoc-AUTES 
Figure S2. Thermogravimetric analysis curves of APMS-3-Fmoc-n samples, where n = (a) 20, (b) 33, (c) 45, (d) 60, (e) 100, (f) 135, (g) 200.

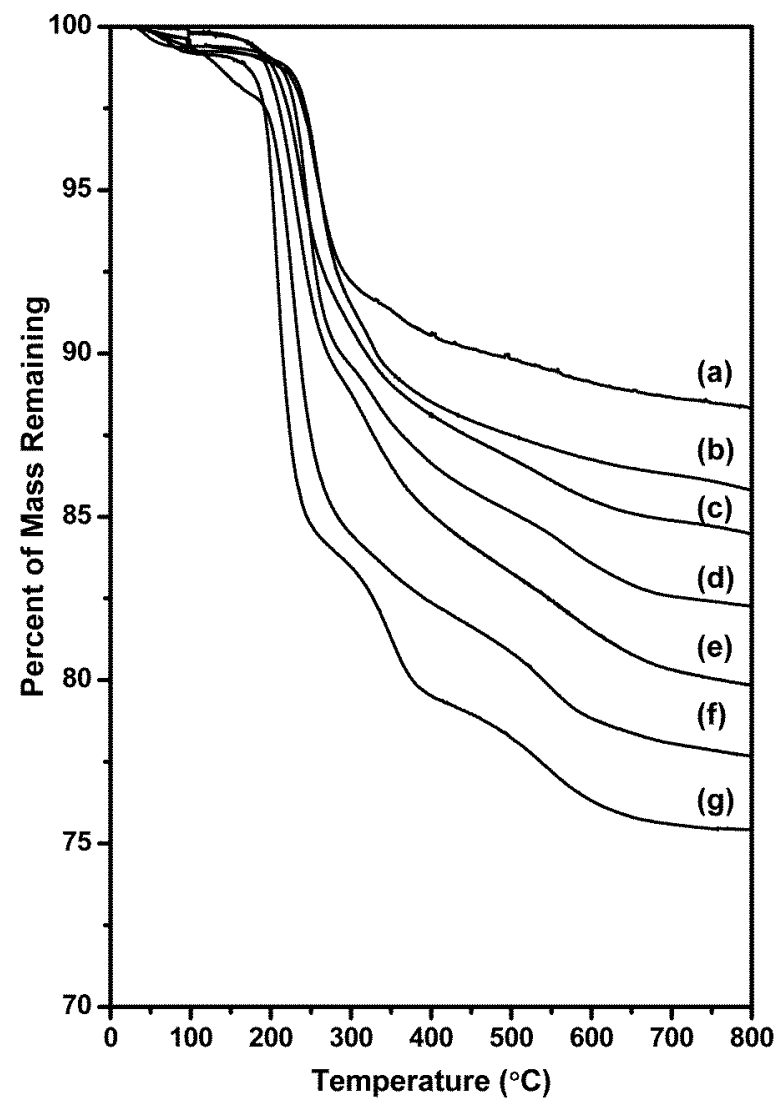


Figure S3. UV/Visible spectroscopy of Fmoc-APTES was used to quantify the amount of organic linker on the surface of APMS. Left panel: UV/Visible spectra of Fmoc-APTES standards between 200 and 350 $\mathrm{nm}$. The arrow indicates increasing concentration. Right panel: Calibration curve for the absorbance of Fmoc-APTES at $290 \mathrm{~nm}$, based on the spectra in the left panel.
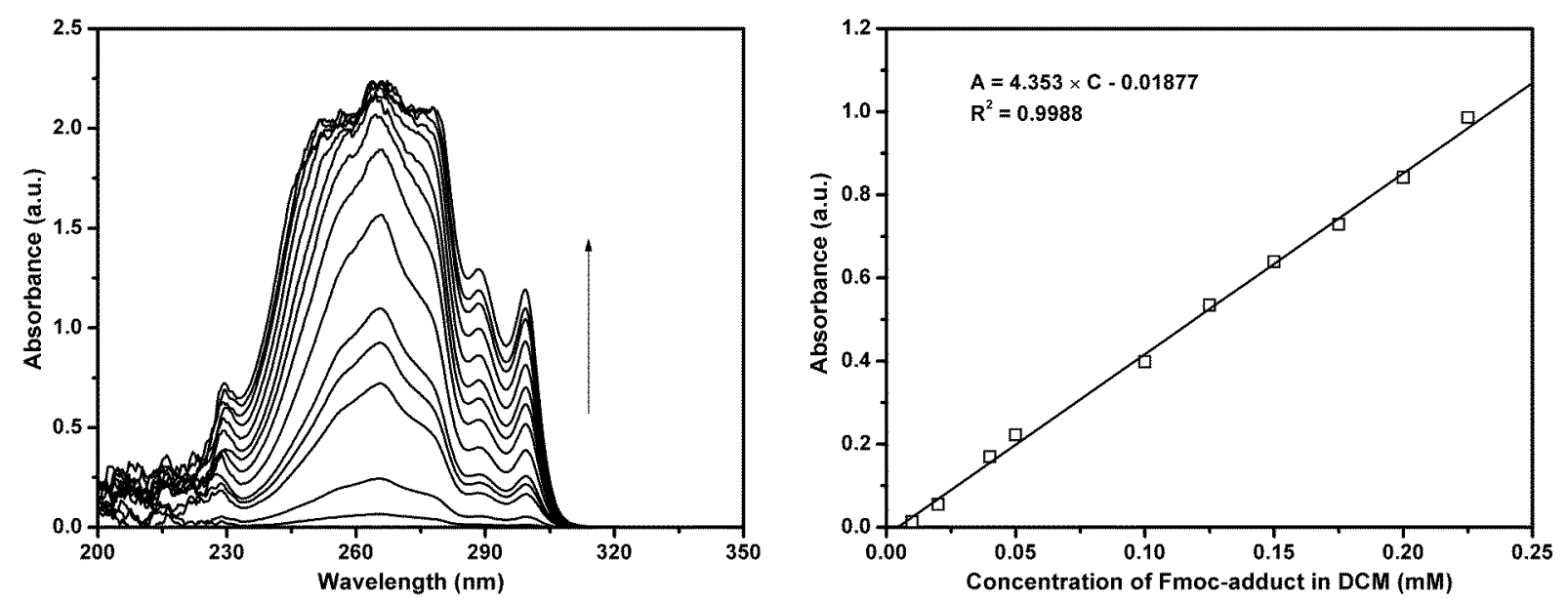
Figure S4. UV-visible spectra of Fmoc-adduct extracted from the APMS-3-Fmoc-n samples after treatment with a solution of HF at room temperature. The peak at $290 \mathrm{~nm}$ was used to quantify the amount of Fmoc-adduct, based on the calibration curve in Figure S3.

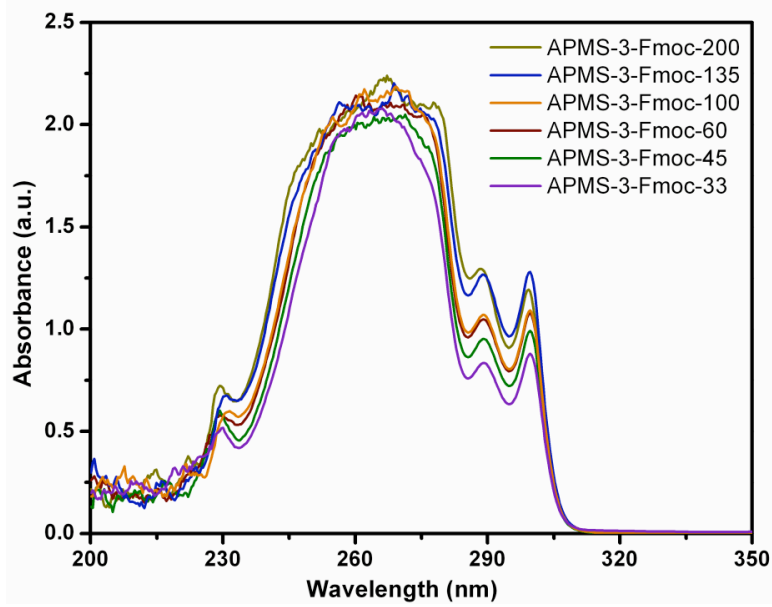


Figure S5. FTIR spectra of (a) APMS and APMS-3-Fmoc-n samples, where n = (b), 20, (c) 33, (d) 45, (e) 60, (f) 100, (g) 135, and (h) 200. The spectrum of Fmoc-APTES is shown in (i).

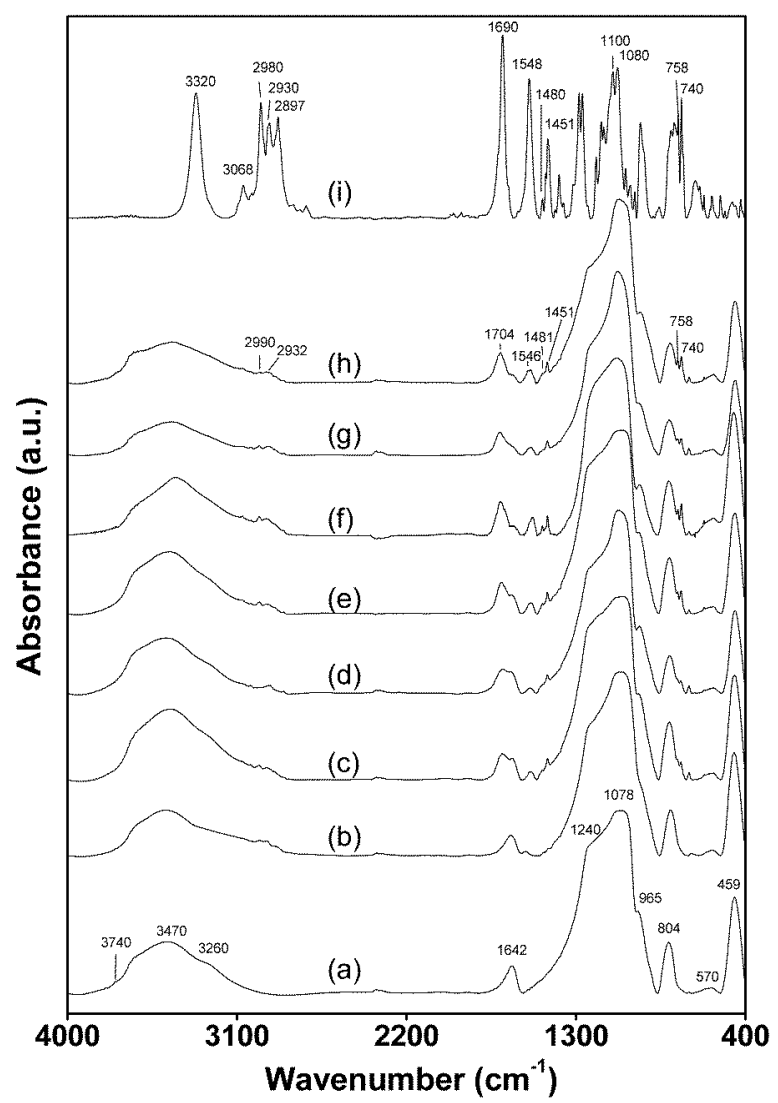


Figure S6. FTIR spectra of selected samples: (a) APMS, (b) APMS-3-Fmoc-135, (c) APMS-3-Fmoc-135 deprotected in 5\% piperidine/DMF for $6 \mathrm{~h}$, (d) APMS-3-Fmoc-135 deprotected in 5\% piperidine/DMF for $24 \mathrm{~h}$, and (e) APTES.

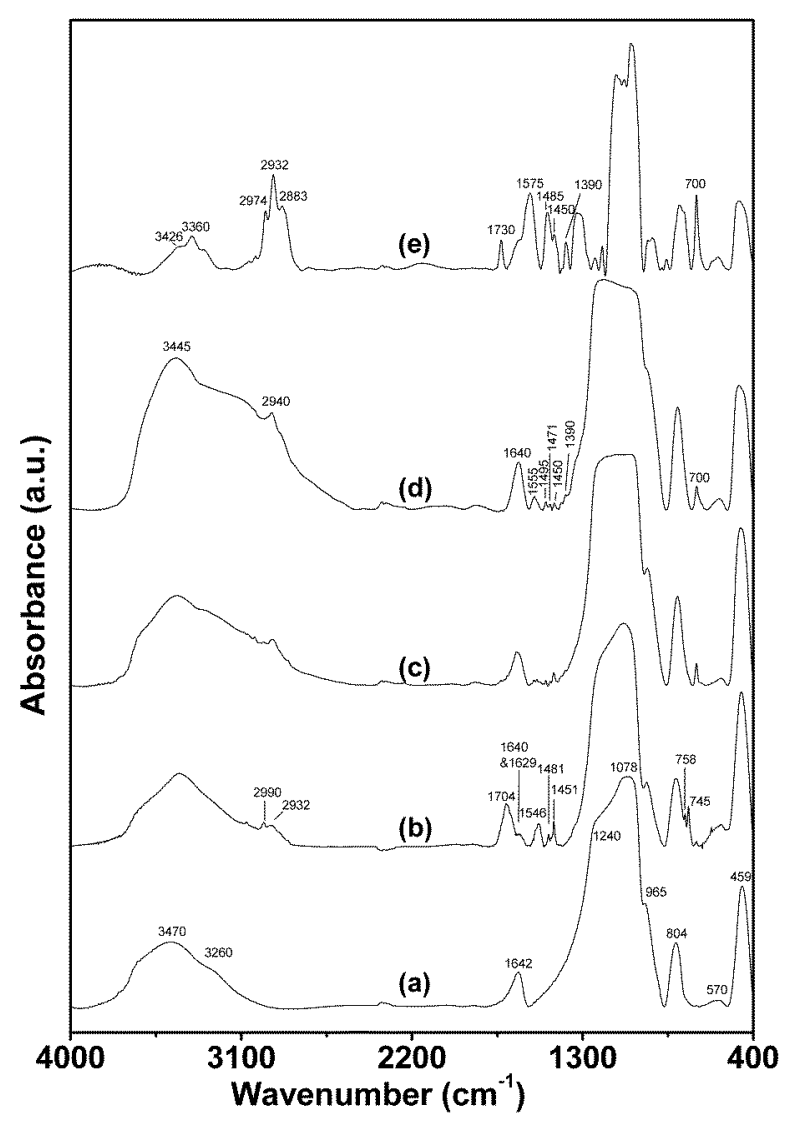


Figure S7. ${ }^{29}$ Si MAS-NMR spectra of (a) APMS, (b) APMS-3-Fmoc-60, and (c) APMS-3-Fmoc-100. Chemical shifts from deconvolution of the spectra are marked, and relative peak areas normalized to the area of the $\mathrm{Q}^{4}$ peak in (a) are given in parentheses.
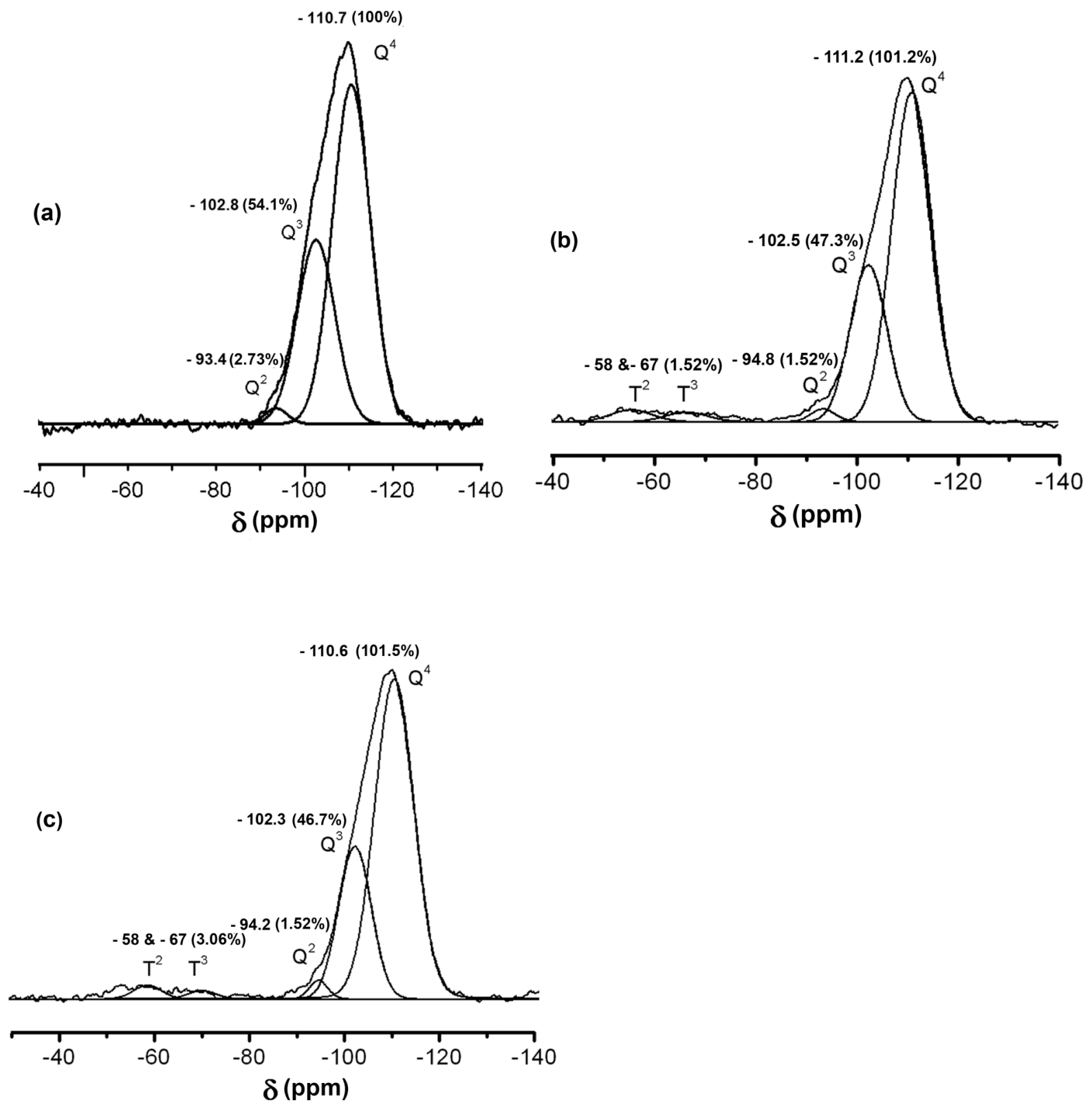
Figure S8. $\mathrm{N}_{2}$ physisorption isotherms (left panel) and pore size distributions (right panel) of (a) APMS and APMS-3-Fmoc-n samples, where $\mathrm{n}=$ (b) 20, (c) 33, (d) 45, (e) 60, (f) 100, (g) 135, and (h) 200.
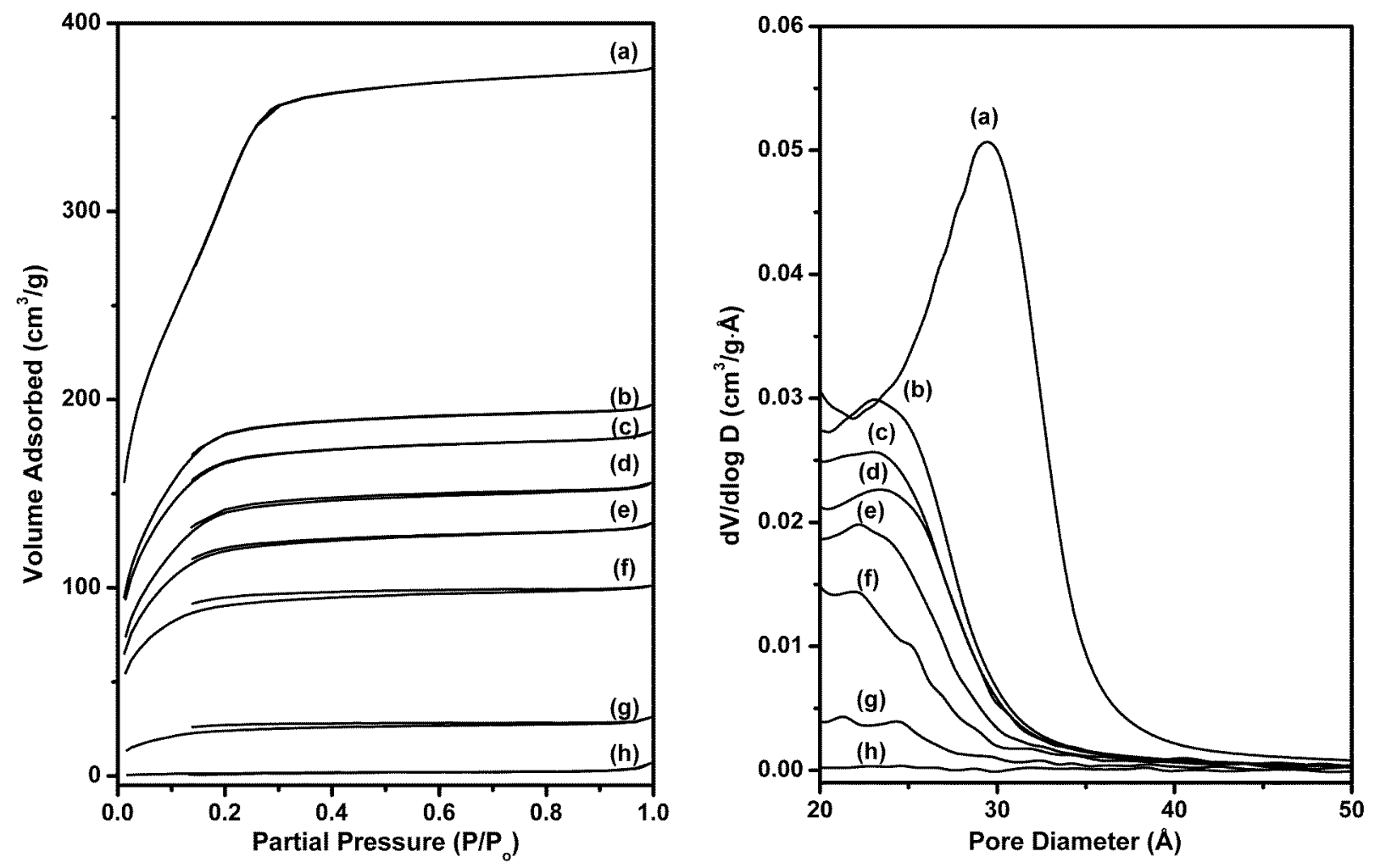
Figure S9. $\mathrm{N}_{2}$ physisorption isotherms (left panels) and pore size distributions (right panels) of selected samples. Top row: (a) APMS, (b) APMS-11-Fmoc-50, and (c) APMS-11-Fmoc-200. Bottom row: (a) Nucleosil, (b) Nucleosil-3-Fmoc-200, and (c) Nucleosil-11-Fmoc-200.
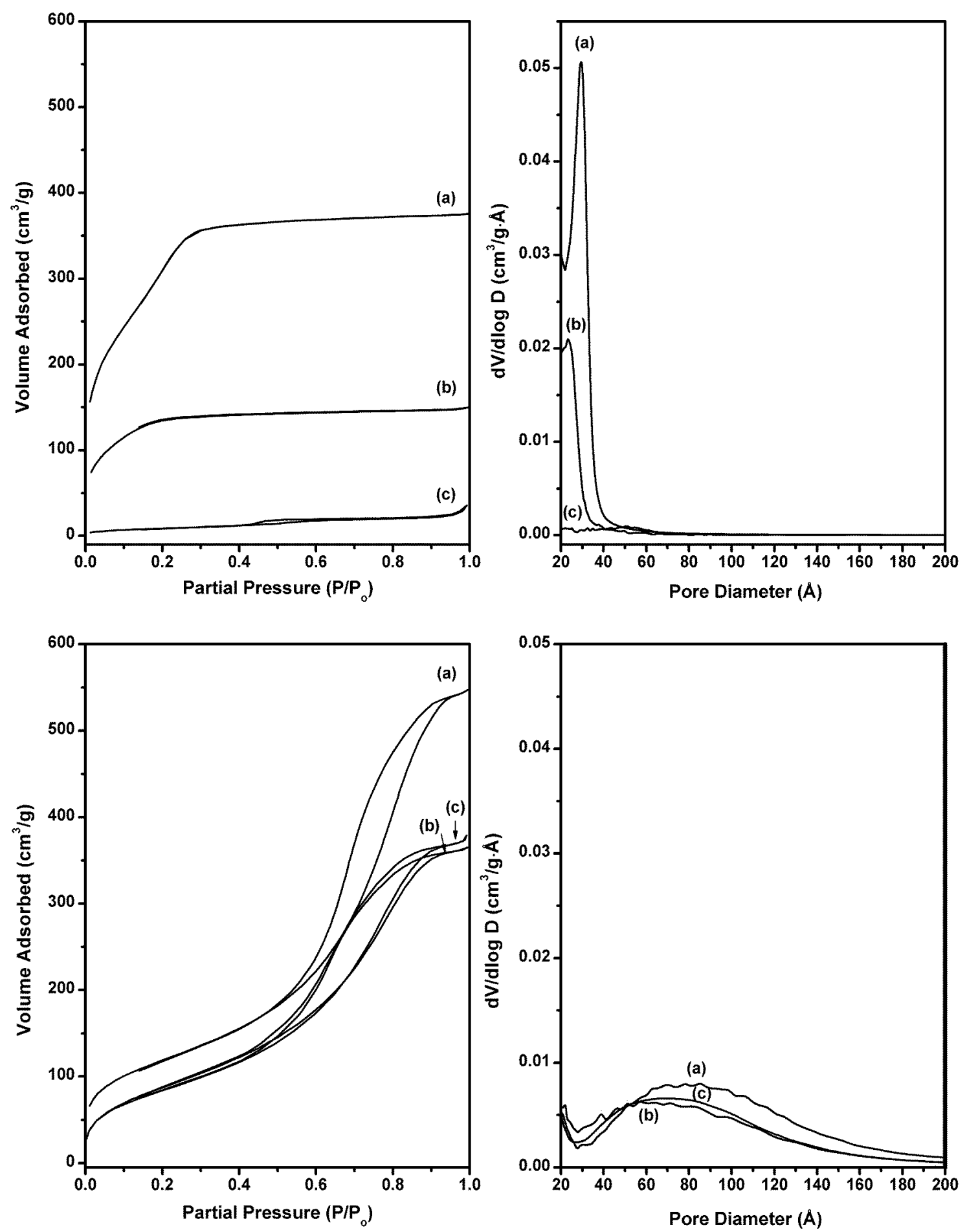
Figure S10. $\mathrm{N}_{2}$ physisorption isotherms (left panel) and pore size distributions (right panel) of selected samples: (a) APMS, (b) APMS-3-Fmoc-135, (c) APMS-3-Fmoc-135 deprotected in 5\% piperidine/DMF for $6 \mathrm{~h}$, (d) APMS-3-Fmoc-135 deprotected in 5\% piperidine/DMF for $24 \mathrm{~h}$.
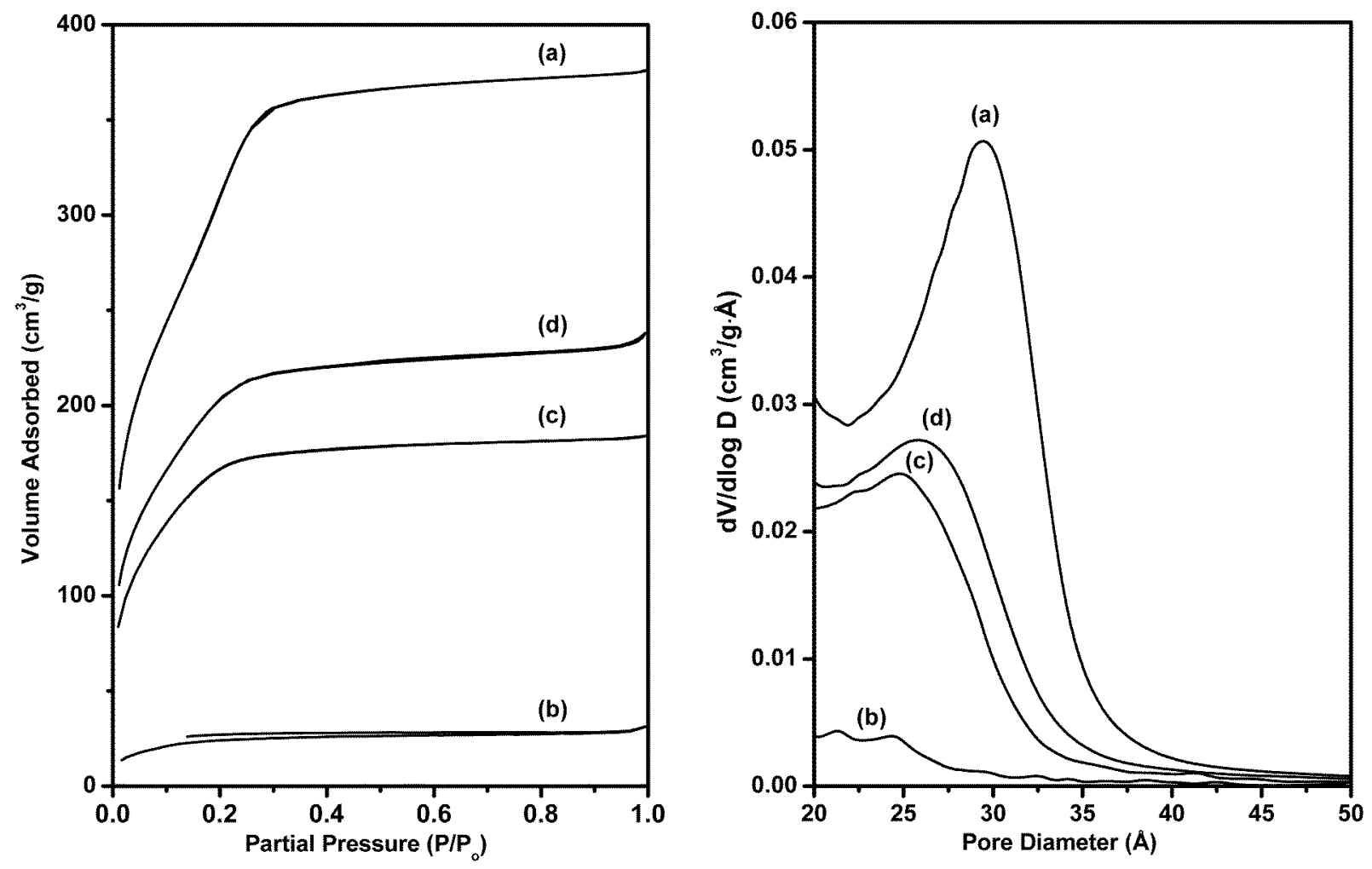
Figure S11. UV-visible spectra of Fmoc-piperidine adduct released from APMS-3-Fmoc-100 in a solution of DMF containing 5\% piperidine at room temperature.

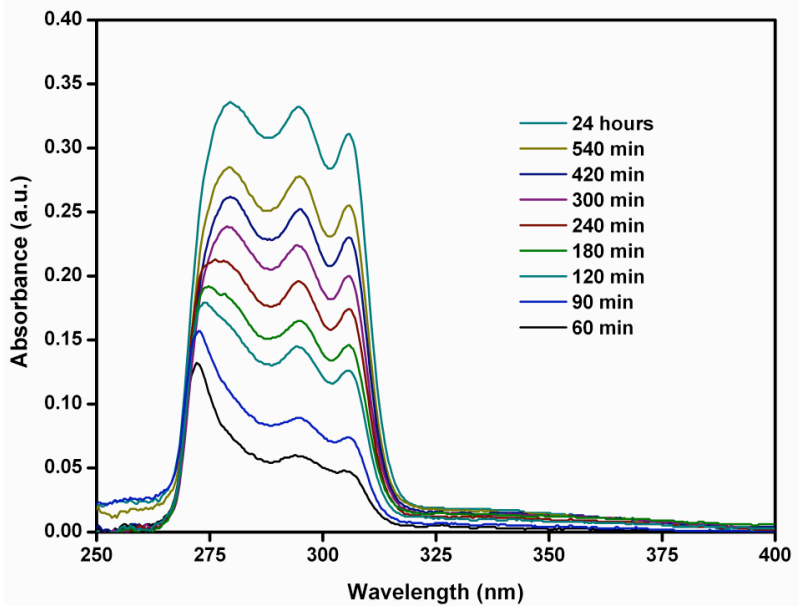


Figure S12. Powder XRD patterns of (a) APMS and APMS-3-Fmoc-n samples, where $n=(b)$ 20, (c) 33, (d) 45, (e) 60, (f) 100, (g) 135, (h) 200.

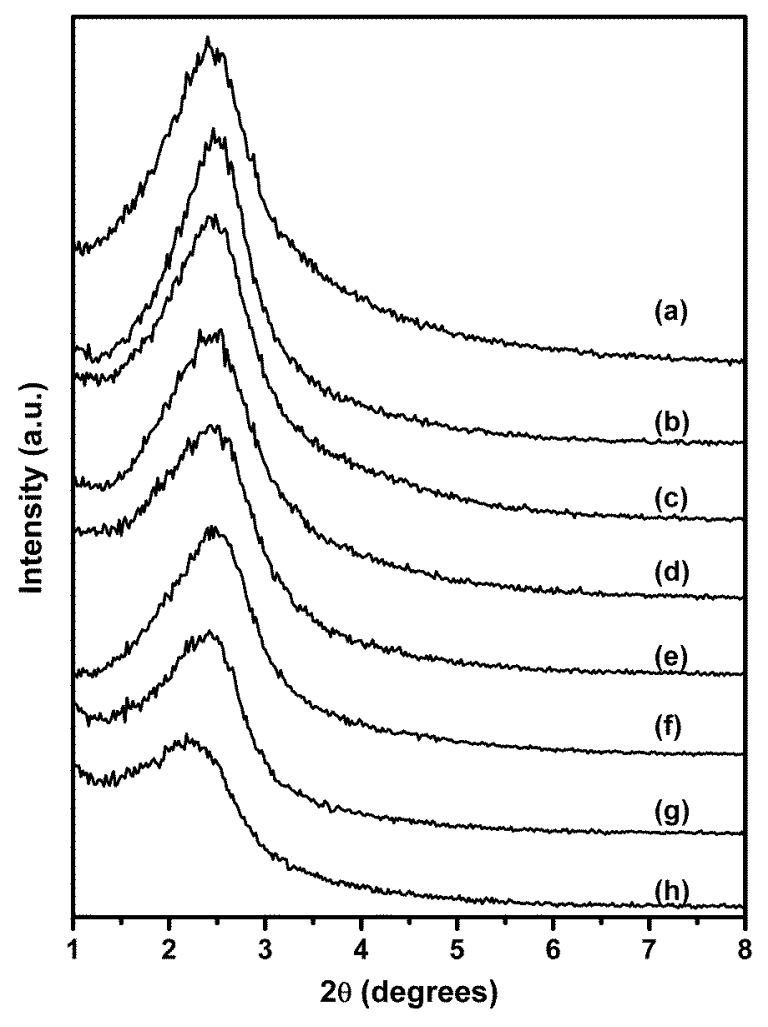

